A METHODOLOGY FOR ENVIRONMENTAL SYSTEMS

MANAGEMENT: DYNAMIC APPLICATION OF THE NESTED

LAGRANGIAN MULTIPLIER METHOD

Fumiko Seo and Masatoshi Sakawa

RR-80-12

March 1980

Reprinted from the IEEE Transactions on Systems, Man, and Cybernetics, volume SMC-9 (12) (1979)

INTERNATIONAL INSTITUTE FOR APPLIED SYSTEMS ANALYSIS

Laxenburg, Austria 
Research Reports, which record research conducted at IIASA, are independently reviewed before publication. However, the views and opinions they express are not necessarily those of the Institute or the National Member Organizations that support it.

Reprinted with permission from IEEE Transactions on Systems, Man, and Cybernetics SMC-9(12): 794-805, 1979.

Copyright @ 1979 The Institute of Electrical and Electronic Engineers, Inc.

All rights reserved. No part of this publication may be reproduced or transmitted in any form or by any means, electronic or mechanical, including photocopy, recording, or any information storage or retrieval system, without permission in writing from the copyright holder. 


\section{FOREWORD}

Many of the problems addressed by the International Institute for Applied Systems Analysis involve decision processes and hierarchical structures with conflicting objectives. Thus, multiobjective decision analysis has been a field of continuing research throughout the life of the Institute.

This report presents a new method for addressing decision-making processes with noncommensurate multiple objectives. It presents both the theory and an application to regional planning for environmental management and industrial reallocation in Japan's Kinki region.

The approach centers its attention on combining analytical aspects of mathematical programming with judgment in decision making to coordinate and adjust conflicting interests.

ANDRZEJ WIERZBICKI

Chairman

System and Decision Sciences Area 


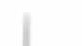




\title{
A Methodology for Environmental Systems Management: Dynamic Application of the Nested Lagrangian Multiplier Method
}

\author{
FUMIKO SEO AND MASATOSHI SAKAWA
}

\begin{abstract}
In this paper an alternative method for solving multiobjective optimization problems is presented. We are especially concerned with bridging a gap between procedures for obtaining the Pareto-optimal solutions and the "best compromised" preferred solution for the decisionmaker. First, the main concepts of the utility approach are briefly reviewed from the point of view of multiobjective systems analysis, and some shortages of this approach are examined. Second, a new method which we call the nested Lagrangian multiplier method (or NLM method) is introduced and compared with precedent devices for the utility approach. The theoretical background is also scrutinized. Third, the use of the NLM method for environmental systems management in the greater Osaka area is demonstrated, providing an example of dynamic application of this method. Finally, it is recalled that utilization of a mathematical optimization method for integrated plannings would simultaneously provide optimal solutions for allocation as well as evaluation problems, based on duality of mathematical programming. A stress is placed on the utilization of dual optimal solutions as a base of evaluation factors.
\end{abstract}

\section{INTRODUCTION}

$\mathrm{E}$ NVIRONMENTAL systems are generally multiobjective, and to analyze them multicriterion functions will be optimized. However, conventional optimization methods which are exclusively concerned with scalar optimization problems are not suitable for finding unique optimal solutions to multiple criteria problems.

The multiple criteria problems have three difficulties. First, the superior solution for all decision variables in multiple criteria problems generally cannot be found because the criteria are usually in conflict with each other. Second, the values of multicriterion functions are generally noncommensurate: the magnitude of the numerical values cannot be measured in a common unit. Third, decisionmaking in the multiple criteria problems is usually under uncertainty. Making decisions for selecting optimal policies cannot be delayed until empirical results of mass observations can be obtained because environmental impacts of policymaking are not only complex but often irreversible.

The first of these difficulties is overcome by finding the

Manuscript received January 3, 1979; revised August 13, 1979.

F. Seo is presently with the International Institute for Applied Systems Analysis, Laxenburg, Austria on leave from the Kyoto Institute of Economic Research, Kyoto University, Kyoto 606, Japan.

M. Sakawa is with the Department of Systems Engineering, Kobe University, Kobe 657, Japan. preferred solution from among a noninferior solution set or Pareto-optimal solution set. This is called a multicriterion optimization problem. Secondly, to overcome the noncommensurateness, an overall evaluation index for multiple criteria functions is quantitatively constructed. This index expresses a value of the decisionmaker's overall preference function defined on the values of the multicriterion functions. ${ }^{1}$ Some devices based mainly on the goal programming approach have been the beginning of this direction [8], [5], [6]. However, in their approaches, proper devices for deriving the overall preference function have been lacking. In their works, the overall preference function is treated as known in advance, and search procedures to maximize this function are only considered. However, the problem is how to derive quantitatively the preference functions which are unknown in advance, and more sophisticated devices for constructing the overall preference function are required. In addition, this process is also under uncertainty, demanding the subjective judgement of the decisionmaker.

Thus, multiobjective optimization problems have two phases: to obtain the Pareto-optimal solutions is an analytical or deterministic phase. To choose the preferred solution among them is a judgmental or subjective phase. For solving the multicriterion optimization problem these two phases shall be combined tactfully.

In general, a multicriterion optimization problem is considered in the following form:

$$
\max _{x \in X}\left\{f_{1}(x), f_{2}(x), \cdots, f_{m}(x)\right\}
$$

where $f_{i}, i=1, \cdots, m$, is a criterion function (or objective function) of an $n$ dimensional decision vector $x . x$ is a constrained set of feasible decision.

In problem (1) $m$ objective functions are usually noncommensurate and in conflict with each other.

\footnotetext{
${ }^{1}$ The multicriterion problems generally reflect diversification of values concerning various alternative courses of action. To incorporate these values into the decisionmaking processes is a main aspect of decision problems. This means to amalgamate the individual's preference orderings into an overall preference ordering for the society. This problem shows another difficulty of the multicriterion optimization problem (Arrow [1], [2], Sage [26]). However, value-systems analysis and group decisionmaking are not discussed in this paper. Instead, a preference function of the decisionmaker is derived with a sophisticated procedure.
} 
There are usually no optimal solutions to the multicriterion optimization problem (1). However, a set of noninferior solutions $x^{*}$ is defined as follows: there does not exist any $x \in X$ such that $f_{r}(x)>f_{r}\left(x^{*}\right)$ for some $r \in J$ and $f_{k}(x) \geq f_{k}\left(x^{*}\right)$ for all $k \in J k \neq r(J$ is an index set whose elements are $\{1,2, \cdots, m\})$. The main aim of multidimensional optimization methods is to select the preferred solution as the best compromised solution from among the noninferior or Pareto-optimal solutions.

Now consider this overall optimization problem (1) in the decomposed form:

$$
\max _{x_{i} \in X}\left\{f_{1}\left(x_{1}\right), f_{2}\left(x_{2}\right), \cdots, f_{m}\left(x_{m}\right)\right\}
$$

where $x_{i}$ is an $n_{i}$ dimensional decision vector in a subsystem $i, i=1,2, \cdots, m$.

To manipulate the noncommensurateness and conflict in problem (2) consider an overall decision problem (3) in the following form:

$$
\max _{x_{i} \in X} U\left\{f_{1}\left(x_{1}\right), f_{2}\left(x_{2}\right), \cdots, f_{m}\left(x_{m}\right)\right\} .
$$

Function $U$ in problem (3) is an overall preference function defined on all the values of the multidimensional criteria function $\left\{f_{i}\left(x_{i}\right)\right\}$. It is called the multiattribute utility function. Measures of effectiveness of each criterion function $f_{i}\left(x_{i}\right)$ are called attributes. $f_{i}$ and $x_{i}$ can also be multiattribute utility functions or single-attribute utility functions. In this case the procedure of sequentially embedding component utility functions to form the composite utility function is called nesting and the overall preference function $U$ expresses a preference hierarchy in the following form $(q<m)$ :

$$
\begin{aligned}
& \max _{x_{i} \in X} U\left[u^{1}\left(x^{1}\right), u^{2}\left(x^{2}\right), \cdots, u^{q}\left(x^{q}\right)\right] \\
&=\max _{x_{i} \in X} U\left[u^{1}\left(u_{1}\left(x_{1}^{1}\right), u_{2}\left(x_{2}^{1}\right), \cdots, u_{q}\left(x_{q}^{1}\right)\right),\right. \\
& u^{2}\left(u_{q+1}\left(x_{q+1}^{2}\right), \cdots, u_{r}\left(x_{r}^{2}\right)\right), \cdots, \\
&\left.u^{q}\left(u_{s+1}\left(x_{s+1}^{q}\right), \cdots, u_{m}\left(x_{m}^{q}\right)\right)\right],
\end{aligned}
$$

where $x^{j}$ is a vector whose component is $x_{i}^{j} x_{i}^{j}$ can also be a vector. $u_{i}\left(x_{i}^{j}\right)$ is a conventional component utility function when $x_{i}^{j}$ is a scalar [25], [27], [14], [15]. Expression (5) shows the nesting of $m$ subsystems into $q$ subsystems where $u_{i}$ can also be a multiattribute utility function. The nesting procedures can be executed one after another in the objectives hierarchy of the stratified systems.

Values of the overall preference function $U$ is utilized as a criterion for determining preference ordering of the decisionmaker and for seeking the preferred solution from among a set of noninferior solutions or a Pareto-admissible frontier. An ordered numerical set of the preference functions composes a family of the preference indifference counters. However, forms of the preference indifference counters are generally unknown in advance. Thus a device with which the preference functions can be seeked will be provided.
Now accepting the decisionmaker's preference system, the preferred solutions are defined by a point where trade-off rates between two values in the Pareto-admissible frontier in an objective function space for problem (1),

$$
\rho_{i j}=\left.\frac{\partial f_{i}}{\partial f_{j}}\right|_{\text {Pareto }},
$$

coincide with the social marginal rate of substitution in the preference indifference counter,

$$
S_{i j}=\left.\frac{\partial f_{i}}{\partial f_{j}}\right|_{\text {Social }},
$$

namely, $\rho_{i j}=S_{i j}$. In other Pareto-optimal solutions, these rates do not coincide, namely $\rho_{i j}>S_{i m}$, or $\rho_{i j}<S_{i j}(i \neq j)$. This coincidence point can be used as the best compromised solution among Pareto-admissible frontier.

In selecting efficient algorithms for seeking best compromised solutions, the following criteria have been suggested by Cohon and Marks [3]: 1) computational feasibility and efficiency, 2) explicit quantification of the trade-offs among objectives, and 3) sufficient information for decisionmaking. Relating to these criteria, especially to the third, an exact representation of the noninferior set (Paretoefficiency frontier) is required. For example, the surrogate worth trade-off (SWT) method [9], [10] appropriately corresponds to these criteria. It compares $\rho_{i j}$ with $S_{i j}$ and places a weight on the difference. This weighting function $W_{i j}\left(\rho_{i j}\right)$ is called the surrogate worth function.

However, with this method, although much effort must be devoted to deriving the noninferior solution set, this is not all necessary for acquiring the preferred solutions, for it is possible to seek them without complete information on the noninferior region. The main point is to check, in the sequential processes of search for the preferred solution, whether or not each solution meets the Paretian criterion. Besides, although the SWT method utilizes analytical solutions in the process of deriving the trade-off rate functions $\rho_{i j}\left(f_{j}\right)$ in the first step, it does not have any sophisticated device for scaling the numerical values of the worth functions $w_{i j}\left(\rho_{i j}\right)$ with cardinal numbers in the second step.

In the next section an alternative method for solving multidimensional optimization problems without comprehensively deriving the Paretian frontier is presented. The core of this new method is the formation of a hierarchical modeling of the multilevel systems, and the direct use of Lagrangian multipliers as shadow prices in the process deriving the preference functions.

\section{Methodology-The Nested Lagrangian MULTIPLIER METHOD}

\section{A. Constructing an Objectives Hierarchy}

To solve multicriterion optimization problem (3) a new method based on decision analysis as well as mathematical programming is proposed.

The hierarchical modeling of the multilevel systems is basically composed of two layers, each of which includes an 


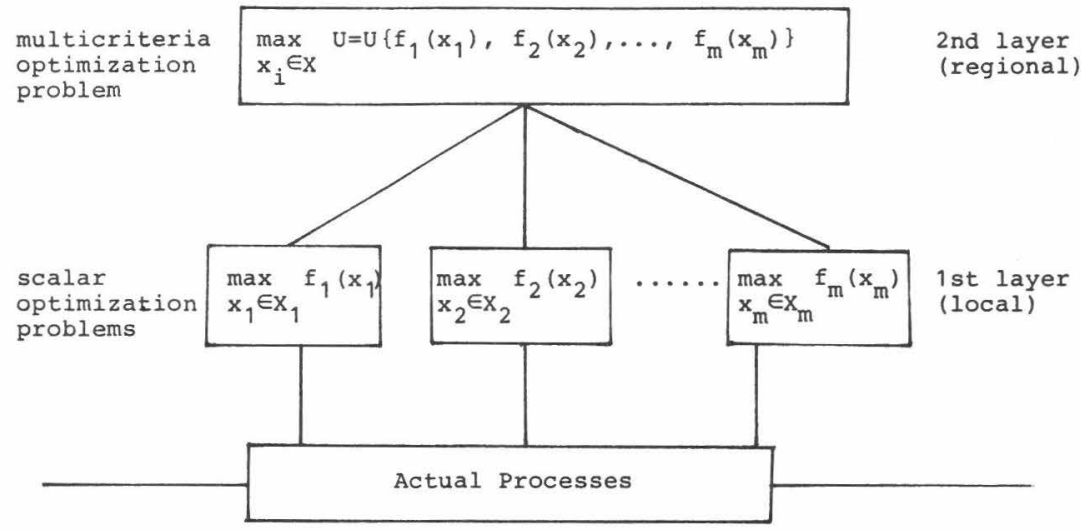

Fig. 1. Systems decomposition and coordination on two layers.

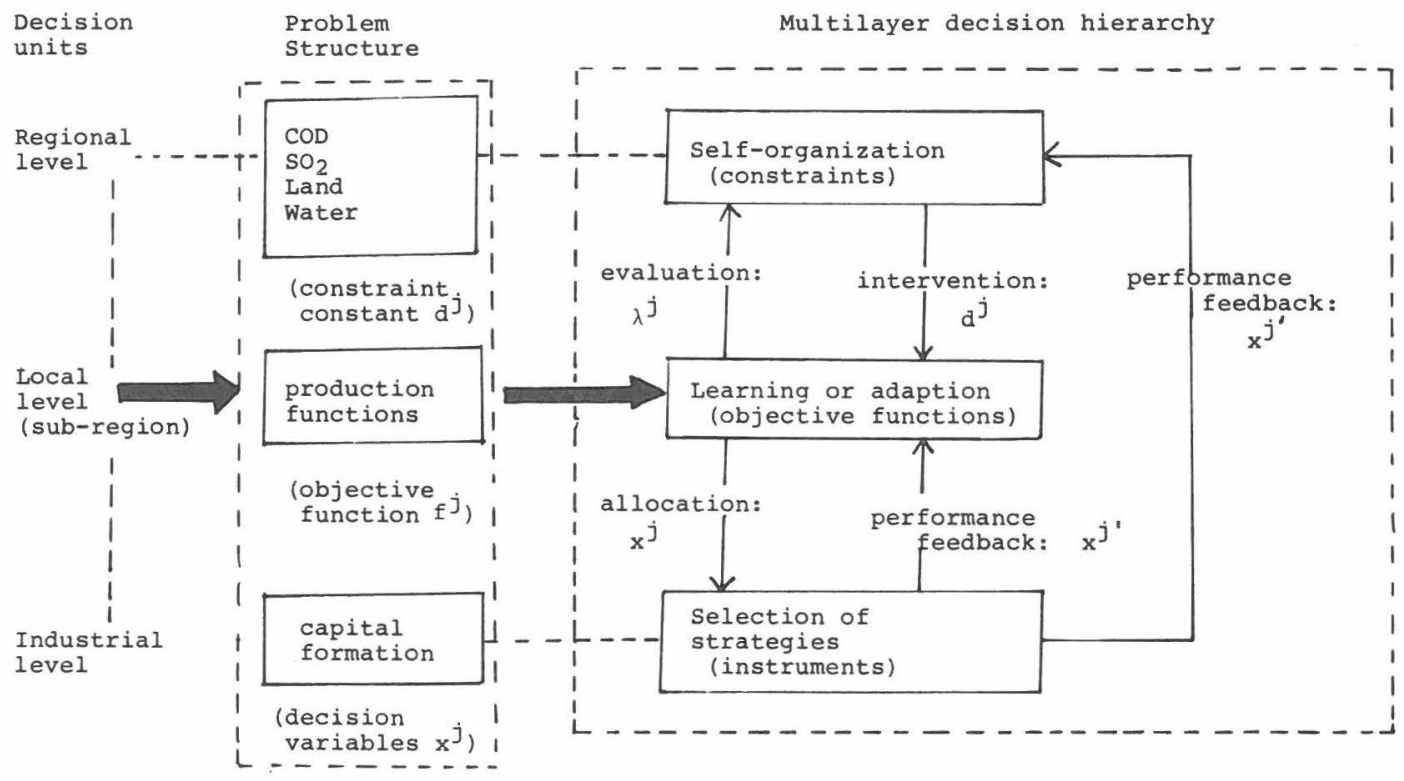

Fig. 2. Functional hierarchy of local-level planning.

objectives decomposition into more stratified subsystems [22].

At the first layer, mathematical programming is applied to the partitioned subsystems. First, the multiple objectives optimization problem (2) in the overall system is decomposed into single-objective optimization problems:

$$
\max _{x_{i} \in X_{i}} f_{i}\left(x_{i}\right), \quad i=1, \cdots, m .
$$

In the subsystems each problem is formulated separately and solved independently, and during these processes an optimal solution to each subproblem (6) is found.

At the second layer, the subsystems (6) are coordinated into an overall system (3): optimal solutions obtained from the first layer optimization processes are combined with a weighting method (Fig. 1). The problem here is to find a more sophisticated weighting method. For this purpose, an efficient nesting algorithm must be developed.

\section{B. Nesting the Shadow Prices}

Now the problem is to present a device for deriving an overall systems evaluation at the second layer based on the first layer estimation. For this purpose a preference hierarchy is constructed in two layers corresponding to the objectives decomposition shown in Fig. 1. Thus the multicriterion optimization problem (2) is converted into the multicriterion decision problem (3) via nested decision problem in multilevel (5), (4).

The Lagrangian multipliers, or a dual optimal solution obtained from mathematical programming, are utilized as a medium for deriving the component utility functions in problem (5). The method is described as follows.

First, overall problem (1) is described in the following decomposed form $(q<m)$, instead of $(2)$, in a hierarchical system:

$$
\max _{x j \in X^{j}}\left\{f^{1}\left(x^{1}\right), f^{2}\left(x^{2}\right), \cdots, f^{q}\left(x^{q}\right)\right\} .
$$

Second, partitioned subproblems are separately formulated as follows:

$$
\max _{x^{j} \in X^{j}} f^{j}\left(x^{j}\right), \quad j=1, \cdots, q .
$$

Here $x^{j}$ is a decision vector and $X^{j}$ is a feasible set of decision 
variables in subsystem $j . f^{j}$ is a scalar-valued objective function.

Mathematical programming for $(8)$ is also considered in a hierarchical structure. Namely, an objective function of mathematical programming represents a "lower-level" objective peculiar to each subsystem. Constraint constants are regarded as "upper-level" objectives which are sent from the "upper-level" decisionmaker. Decision variables are a normative instrument for achieving these objectives and regarded as the lowest level objectives. Thus, formulations of mathematical programming are considered in the framework of a hierarchical systems structure. In Fig. 2 the problem structure is depicted for three level planning-regional, local, and industrial. Here, mathematical programming problem (8) is formulated as a local-level planning. Mathematical programming is solved as a primal-dual problem and dual solutions $\lambda^{j}$ as well as primal solutions $x^{j}$ are obtained. The framework includes a feedback process. The "local-level" decisionmaker compares the optimal value $x^{j}$ with the actual performance $x^{j^{\prime}}$, and can modify his instruction for the local-level planning.

Third, the evaluation factor for the component utility function will be defined. Let us consider a mathematical programming formulated in each subsystem $j, j=1, \cdots, q$ :

$$
\begin{aligned}
\max \quad f^{j}\left(x^{j}\right) & \\
\text { subject to } \quad h_{i}^{j}\left(x^{j}\right) & \leq d_{i}^{j}, \\
i & =1, \cdots, J_{r} \\
g_{s}^{j}\left(x^{j}\right) & \leq b_{s}^{j}, \\
s & =J_{r}+1, \cdots, J_{n},
\end{aligned}
$$

where $f^{j}\left(x^{j}\right)$ is a scalar-valued objective function. Constraint (10) shows a target (soft) constraint imposed by the upperlevel decisionmaker, and constraint (11) a technical (hard) constraint restricted by technological conditions. $x^{j}$ is a $n^{j}$ dimensional vector of decision variables in the subproblem $j$. $d_{i}^{j}$ and $b_{s}^{j}$ are scalar values of constraint constants. Then the Lagrangian function is formulated:

$$
\begin{aligned}
L^{j}\left(x^{j}, \lambda^{j} \mid d^{j}, b^{j}\right)=f^{j}\left(x^{j}\right)-\sum_{i=1}^{J_{r}} & \lambda_{i}^{j}\left(h_{i}^{j}\left(x^{j}\right)-d_{i}^{j}\right) \\
& -\sum_{s=J_{r}+1}^{J_{n}} \lambda_{s}^{j}\left(g_{s}^{j}\left(x^{j}\right)-b_{s}^{j}\right) .
\end{aligned}
$$

The inverse of the Lagrangian multiplier in optimal $1 / \lambda_{i}^{j}$ is an opportunity cost of $i$ th constraint constants $d_{i}^{j}$ traded-off to one additional unit of the objective function $f^{j}$ because $1 / \lambda_{i}^{j}=\partial d_{i}^{j} / \partial f^{j}$ in optimal. Thus, the larger $\lambda_{i}^{j}$ is, then the smaller the opportunity cost of $d_{i}^{j}$ in terms of one marginal unit of sacrifice of $f^{j}$ is. In other words, a large value of $\lambda_{j}^{i}$ (shadow price) shows that the degree of satisfaction for present performance level of $d_{i}^{j}$, the "upper-level" objective, is already high in terms of $f^{j}$, the "lower-level" objective.

This interpretation of the shadow prices is almost the same as by Luenberger [21] and Intriligator [12], but is a new version based on the hierarchical structure of mathematical programming.

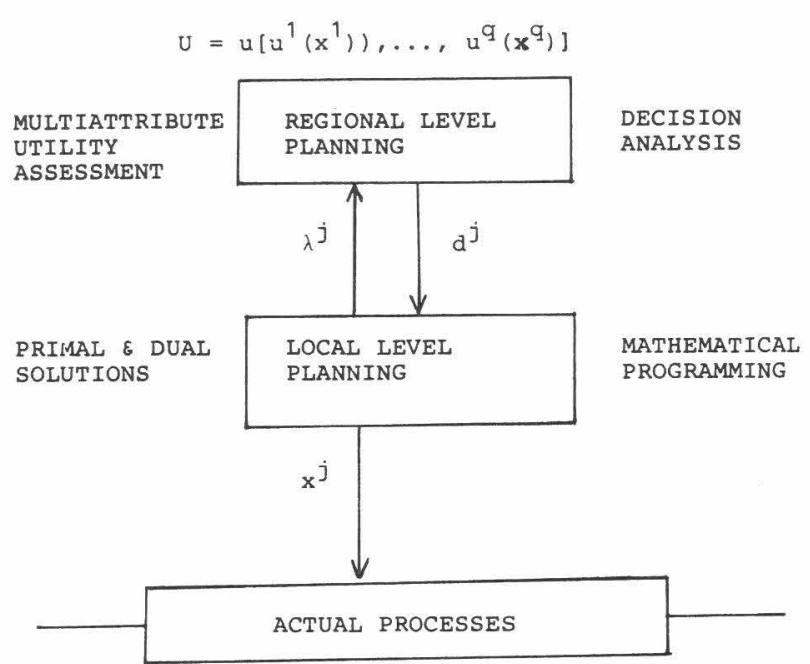

Fig. 3. Structure of three-level planning.

Fourth, transforming the shadow prices into component utility functions. Based on our interpretation of the shadow prices, we utilize the shadow prices as an inverse image of the utility functions in the lower level. Because numerical values of the shadow prices correspond to a preference ordering of the decisionmaker, numerical valuation of utilities is determined by a linear transformation, according to the Von Neumann-Morgenstern theorem (see next section).

In practice, we choose $0<\underline{\lambda}_{i}^{j}<\lambda_{i \min }^{j}$ at $u_{i}\left(\underline{\lambda}_{i}^{j}\right)=0$ and $\bar{\lambda}_{i}^{j}>\lambda_{i \max }^{j}>0$ at $u_{i}\left(\bar{\lambda}_{i}^{j}\right)=1$, where $\underline{\lambda}_{i}^{j}$ shows a lower bound of $\lambda_{i}^{j}$ and $\bar{\lambda}_{i}^{j}$ shows an upper bound of it. Thus, we calculate a linear equation passing through the two points $\bar{\lambda}_{i}^{j}$ and $\underline{\lambda}_{i}^{j}$ as follows:

$$
u_{i}\left(x^{j}\right)=u_{i}\left(\lambda_{i}^{j}\left(x^{j} ; d_{i}^{j}\right)\right)=-a_{i}^{j}+c_{i}^{j} \lambda_{i}^{j}\left(x^{j}\right) .
$$

The $u_{i}\left(\lambda_{i}^{j}\left(x^{j}\right)\right)$ is a component utility function which is related to a target constraint $i$ in subproblem $j$.

Thus, using the redefined concept of the component utility function, we can get alternative expressions as a dual system for the multicriterion decision problem (4) and (5):

$$
\begin{aligned}
& \max _{x j \in X} u\left\{u^{1}\left(x^{1}\right), u^{2}\left(x^{2}\right), \cdots, u^{q}\left(x^{q}\right)\right\} \\
&=\max _{x^{j} \in X} u\left\{u ^ { 1 } \left(\lambda^{1}\left(x^{1}\right), u^{2}\left(\lambda^{2}\left(x^{2}\right), \cdots,\right.\right.\right. \\
&\left.u^{q}\left(\lambda\left(x^{q}\right)\right)\right\}, \\
&= \max _{x j \in X} u\left\{u ^ { 1 } \left\{u_{1}\left(\lambda_{1}^{1}\left(x^{1}\right)\right), u_{2}\left(\lambda_{2}^{1}\left(x^{1}\right)\right), \cdots,\right.\right. \\
&\left.u_{q}\left(\lambda_{q}^{1}\left(x^{1}\right)\right)\right\}, \\
& u^{2}\left\{u _ { q + 1 } \left(\lambda_{q+1}^{2}\left(x^{2}\right), \cdots,\right.\right. \\
&\left.u_{\gamma}\left(\lambda_{\gamma}^{2}\left(x^{2}\right)\right)\right\}, \cdots, \\
& u^{q}\left\{u_{s+1}\left(\lambda_{s}^{q}+1\left(x^{q}\right)\right), \cdots,\right. \\
&\left.\left.u_{m}\left(\lambda_{m}^{q}\left(x^{q}\right)\right)\right\}\right]
\end{aligned}
$$

where $x^{j}$ is a set of primal optimal solutions and $\lambda^{j}$ is a set of dual optimal solutions in subproblem $j$.

The structuring of redefined problems is depicted in Fig. 3. 
At the first layer, a set of the Lagrangian multipliers $\lambda^{j}\left(x^{j}\right)=\left\{\lambda_{i}^{j}\left(x^{j}\right)\right\}$ as well as a set of primal optimal solutions $x^{j}\left(\lambda^{j}\right)$ is derived in solving a mathematical programming for subproblem $j, i=1, \cdots, J_{r}$. At the second layer, the component utility functions $u^{j}\left(x^{j}\right)=\left\{u_{i}\left(\lambda_{i}^{j}\left(x^{j}\right)\right\}, j=1, \cdots, q\right.$, are derived. Then a nesting procedure is executed based on multiattribute utility analysis and multiattribute utility functions are derived in the stratified system. Finally an overall preference function is constructed as an overall multiattribute utility function.

Thus, this method is mainly based on utilizing the Lagrangian multipliers in mathematical programming, transforming them into component utility functions and nesting them into multiattribute utility functions. This is called the nested Lagrangian multiplier (NLM) method [28], [30].

\section{The Concept of the Component Utility Function}

To explain the processes for deriving the component utility function $u_{i}\left(\lambda_{i}^{j}\left(x^{j}\right)\right)$, first the Lagrangian Multiplier in optimal is defined as an inverse image of the component utility functions.

Define a mapping $\Psi$ such that $\Psi: \Lambda \rightarrow \Upsilon$. Let $\lambda \in \Lambda, u \in \Upsilon$, and $\Psi(\Lambda)=\{\Psi(\lambda) \geq 0 \mid \lambda>0, \lambda \in \Lambda\} . u$ is an image of $\lambda$ by $\Psi$. $u$ as well as $\lambda$ is scalar. Let a subset of the set $\Upsilon$ be $\mathscr{U} . \mathscr{P}(\Upsilon)$ is a power set of $\Upsilon$.

$$
\text { In } \mathscr{U} \in \mathscr{P}(\Upsilon), \Psi^{-1}(\mathscr{U})=\{\lambda \mid \lambda \in \Lambda, \Psi(\lambda) \in \mathscr{U}\}
$$

is an inverse image of $\mathscr{U}$.

Second, following Von Neumann and Morgenstern's theorem [23], it is shown that positive linear transformation of $\lambda$ to $u$ is admissible.

Define a system of relation $A=\langle\Omega, R\rangle$ and call it the preference relation $A$. Here $\Omega$ is a nonempty set and $R$ is a binary relation defined on elements of $\Omega$.

Definition 1 (preference relation $A$ ): If $R$ is a binary relation on set $\Omega$ and if $\mathscr{X}, \mathscr{Y}, \mathscr{Z} \in \Omega$, then the preference relation $A$ on individual choices satisfies the following axioms:

1) Transitivity: if $\mathscr{X} R \mathscr{Y}, \mathscr{Y} R \mathscr{Z}$, then $\mathscr{X} R \mathscr{Z}$

2) Weak connectivity: $\mathscr{X} R \mathscr{Y}$, or $\mathscr{Y} R \mathscr{X}$

3) Nonsatiety: if $\mathscr{X}>\mathscr{Y}$ then $\mathscr{X P O}$

4) Continuity: if $\mathscr{X} R \mathscr{Y}$ and $\mathscr{Y} R \mathscr{Z}$, then there is a real number such that $0 \leq \alpha \leq 1$ and $[\alpha \mathscr{X}+(1-\alpha) \mathscr{Z}] I \mathscr{Y}$.

Here $R$ is "prefer to" $(P)$ or "indifferent to" $(I)$.

Definition 2 (weak ordering): $R$ on a set $\Omega$ is weak ordering if and only if transitivity and connectivity are satisfied.

According to Von Neumann and Morgenstern's theorem, Theorem 1 on the preference relation $A$ is derived [20].

Theorem 1 (Von Neumann-Morgenstern): Under preference relation $A$, there exists a real-valued function $S$ defined on $\Omega$ such that, for every $\mathscr{X}$ and $\mathscr{Y}$ in $\Omega$ and a parameter $\alpha$ in an interval $[0,1]$,

1) $\mathscr{X} R \mathscr{Y}$ if and only if $S(\mathscr{X}) \geq S(\mathscr{Y})$

2) $S\{\alpha \mathscr{X}+(1-\alpha) \mathscr{Y}\}=\alpha S(\mathscr{X})+(1-\alpha) S(\mathscr{Y})$.

Moreover, if $S^{\prime}$ is any other function satisfying 1) and 2 ), then $S^{\prime}$ is related to $S$ by a positive linear transformation.

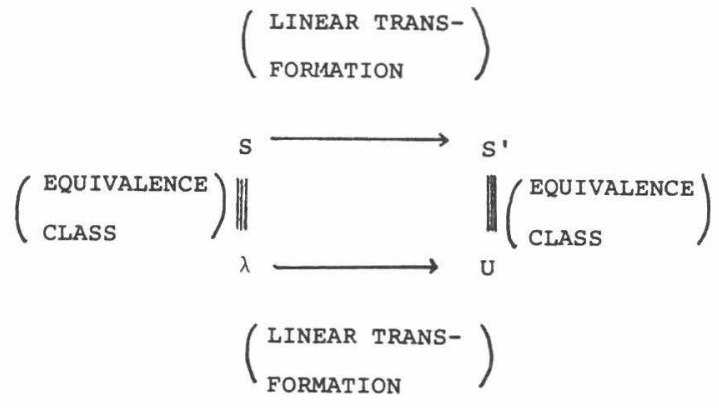

Fig. 4. Derivation of utility function.

The theoretical background of the NLM method is based on the following proposition.

Proposition: According to an interpretation of the Lagrangian multiplier $\lambda$ as a shadow price, $S$ in Theorem 1 is replaced with $\lambda$.

This proposition is based on the fact that $\lambda$ is in an equivalence (namely, reflexive, symmetric, and transitive) class of $S$ in Theorem 1 based on our interpretation of the Lagrangian multipliers. Now these concepts are defined [7].

Definition 3 (equivalence): A binary relation $R$ on $\Omega$ is an equivalence when it is reflexive, symmetric, and transitive.

Definition 4:

1) A binary relation $R$ on a set $\Omega$ is reflexive if $S R S$ for every $S \in \Omega$.

2) A binary relation $R$ on a set $\Omega$ is symmetric if $S R \lambda \rightarrow \lambda R S$ for every $S, \lambda \in \Omega$.

Definition 5 (equivalence classes): The two elements $\lambda$ and $S$ of a set $\Omega$ are in an equivalence class when they are equivalent. If a binary relation $R$ is an equivalence, then $R(S)=\{\lambda: \lambda \in \Omega$ and $\lambda R S\}$ is the equivalence class generated by $S$.

The equivalence set is a set of the equivalence classes. Because in any pair of $\lambda, S \in \Omega, \lambda R \lambda, \lambda R S \rightarrow S R \lambda$, and transitivity can always be assumed based on the interpretation of Lagrangian multipliers as shadow prices, a set of Lagrangian multipliers $\Lambda=\{\lambda\}$ on a decision problem $\mathscr{D}(\Lambda \mid \lambda \in \Omega)$ and a set of $S$ defined on $\Omega$ in Theorem 1 are in an equivalence class defined on $\Omega$. Thus, Theorem 2 and Theorem 3 are derived.

Theorem 2: For every $\mathscr{X}$ and $\mathscr{Y}$ in the set $\Omega$ defined under the preference relation $A$, the following properties are preserved for the Lagrangian multiplier $\lambda$ in optimal:

1) $\mathscr{X} R \mathscr{Y}$ if and only if $\lambda(\mathscr{X}) \geq \lambda(\mathscr{Y})$

2) $\lambda\{\alpha \mathscr{X}+(1-\alpha) \mathscr{Y}\}=\alpha \lambda(\mathscr{X})+(1+\alpha) \lambda(\mathscr{Y})$ where $\mathscr{X}$ and $\mathscr{Y}$ are some implicit evaluation factors.

Theorem 3 (derivation of the utility concept): A Lagrangian multiplier $\lambda$ can be positive-linearly transformed to a numerical utility $u$ defined on a value between zero and one.

The basic idea behind deriving the component utility function is shown in Fig. 4. For the numerical utility, although differences between utilities are numerically measurable, the position of origin and the unit of a numerical scale for the utilities can be decided arbitrarily. This type of scale is called an interval scale. 


\section{Remarks}

Although our method is on the line of the surrogate worth trade-off (SWT) method [9], [10] and the multiattribute utility function (MUF) method [14], [15] and has characteristics similar to them, it also has several different properties.

1) In solving a multiple criteria optimization problem, although the SWT method considers the problem as a vector optimization problem, in practice it treats all the objective functions, except one, as constraints. In consequence, the Lagrangian multipliers are interpreted as the trade-off rate functions between the objectives. The worth assessment is indirectly given to the trade-off rate functions instead of to the objective functions. In the NLM method, from the beginning a vector optimization problem is treated as a set of scalar optimization problems at the lower level based on the construction of hierarchical modeling. Further, each mathematical programming formulated in the subsystems is considered to be a composite of objectives at multilevels. According to the problem formulation structured at multilevels, the Lagrangian multipliers are utilized for measuring the performance of upper level objectives in terms of the lower level objectives in the multiechelon systems. Thus the worth assessment is directly given to the Lagrangian multipliers in optimal.

2) In the NLM method, the device for deriving the utility function from the Lagrangian multipliers is simply the conversin of scale. In this technique, which differs form the SWT method, worth assessment has already been performed in the calculation of shadow prices. The Utilization of the Lagrangian multipliers for derivation processes of the component utility functions in the NLM method greatly reduce indeterminateness and arbitrariness in the first stage of worth assessment.

3) In actual environmental systems, the introduction of decisionmaking under uncertainty in terms of judgmental probability is inevitable. In view of this fact a coordination or weighting procedure based on subjective judgments by the decisionmaker is introduced at the upper layer of a stratified system. Thus decision analysis for systems coordination is combined with analytical solutions derived from mathematical programming. In addition, getting the indifferent trade-off ratios numerically is a more efficient process because the indifference experiments are performed in terms of the normalized utility functions in this method.

4) In the NLM method negative values of utility functions, which have been derived from zero-valued Lagrangian multipliers combined with inactive constraints in optimal, are utilized as switching parameters. With these values it is possible to identify needs for policymaking in other supplementary fields.

\section{Demonstration}

To demonstrate the nested Lagrangian multiplier method, an environmental management program in the industrialized greater Osaka area is evaluated.

First, a hierarchical modeling of an overall system is performed. A systems decomposition at multilevel is utilized to structure the regional complex problematique. In this case, two-layer planning, regional and local level, is used. At the first layer, mathematical programming is solved to obtain the analytical solution for each subsystem in the local level. At the second layer, decision analysis is applied to evaluate and to coordinate the first-layer solutions.

For an overall regional system, temporal decompositions (short term: $t=1,2$; intermediate term: $t=3,4$; and long term: $t=5$ ) as well as regional decompositions (Osaka and East Osaka: Yao, Daito, and Higashi-Osaka) are performed. A functional decomposition for the local-level planning is the same as shown in Fig. 2.

Second, at the first layer, local environmental management problems are formulated, and mathematical programming is applied in each subregion. The parameters have specific characteristics for each subregion. The problem formulation is as follows:

$$
\begin{aligned}
& \operatorname{maximize} F(t)=\int_{t_{0}}^{t_{1}} \sum_{j=1}^{p} A_{j} e^{\mu j} K_{j}(t)^{1-b_{j}} L_{j}(t)^{b_{j}} d t \\
& \text { subject to } \sum_{j=1}^{p}\left(\omega_{j}^{i} e^{-\rho i t} / k_{j}\right) K_{j}(t) \leq \tau^{i}(t), \\
& \left(t=1, \cdots, 5 ; i=\mathrm{COD}, \mathrm{SO}_{2}\right)
\end{aligned}
$$

$\sum_{j=1}^{p} \gamma_{j}^{i}(t) / k_{j} \cdot K_{j}(t) \leq \Gamma^{i}(t)$,

$$
\begin{gathered}
(t=1, \cdots, 5 ; i=\text { land, water }) \\
\sum_{j=1}^{p} K_{j}(t) / \sum_{j=1}^{p} L_{j}(t) \leq q_{t 0}, \quad(t=1, \cdots, 5) \\
K_{j t_{0}} e^{-\pi t} \leq K_{j}(t) \leq K_{j t_{0}} e^{\pi^{\prime} t} \\
L_{j t_{0}} e^{-\pi t} \leq L_{j}(t) \leq L_{j t_{0}} e^{\pi^{\prime} t}, \quad \\
(j=1, \cdots, p ; t=1, \cdots, 5)
\end{gathered}
$$

where objective function (17) is the sum of the dynamic production function for each industry $j$. Constraints (18) and (19) are target constraints and show environmental as well as resource constraints, where $\omega_{j}^{i}$ and $\gamma_{j}^{i}$ are unit loads of environment and resource factor $i\left(\mathrm{COD}, \mathrm{SO}_{2}\right.$; land, water) per industrial shipment (one million yen) in industry $j$. It is supposed that these parameters change as time passes. $k_{j}$ is a capital coefficient in industry $j$. Constraint constants on the right side $\tau^{i}$ and $\Gamma^{i}$ are assigned by the upper-level decisionmaker and also change with time. An example for Osaka City is depicted in Fig. 5. Constraint (20) is a technical constraint and shows that the total capital-labor ratio cannot exceed its present level. It has been shown that, as a result, constraint (20) is generally inactive. Constraints (21) and (22) are frictional constraints for capital and labor transfer among industries. The number of industries varies from 15 to 20 in each subregion. Each local problem includes 150 to 200 decision variables and 25 constraints excepting the upper- and lower-bound constraints (21) and (22).

By solving mathematical programming problems, we intend to perform a dynamic assessment for the environmental management program. Actually, assessments of the 


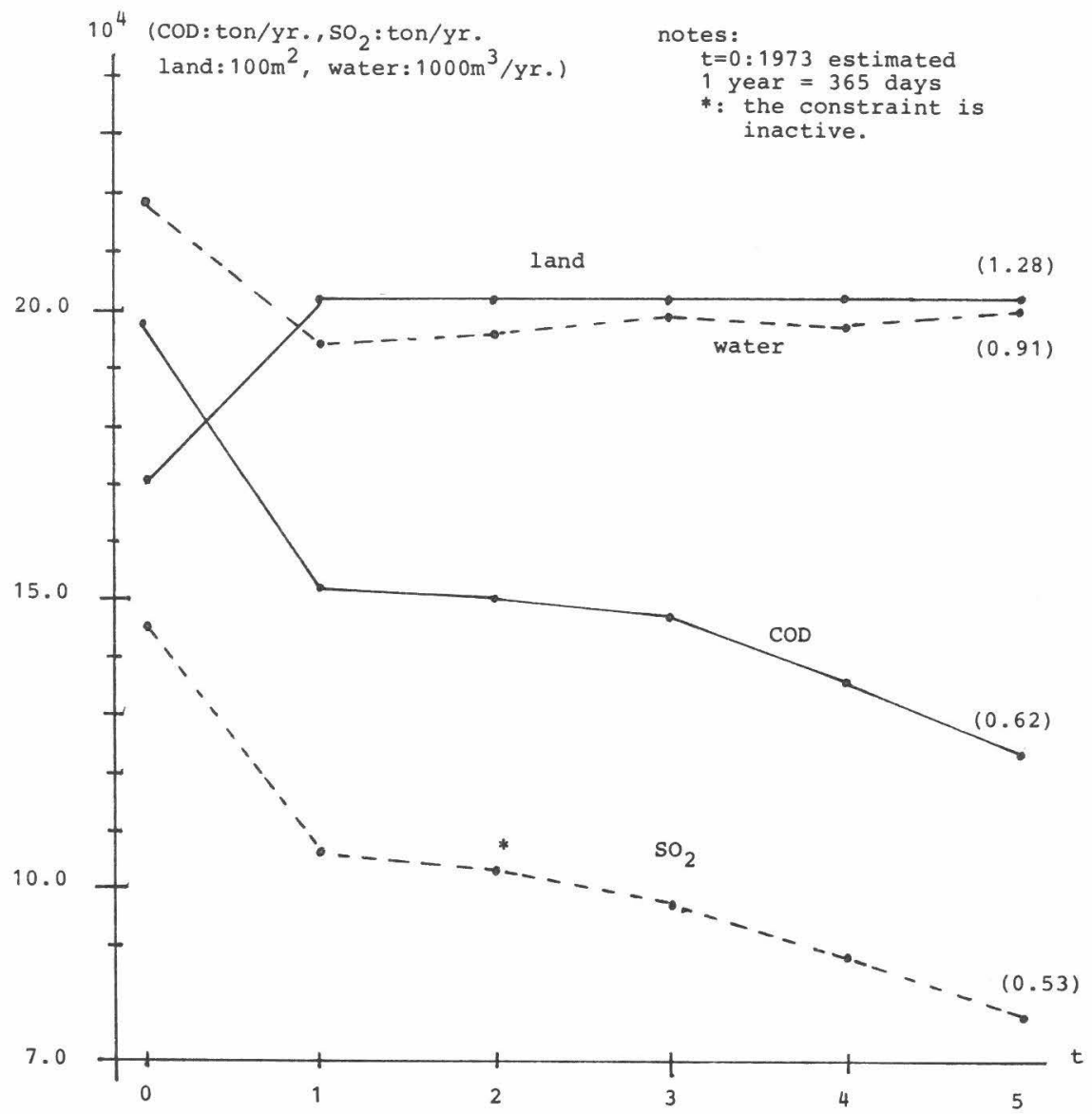

Fig. 5. Environmental restrictions in Osaka City.

five two-year periods are executed in discrete versions of the dynamic problems. The following has been assumed.

1) The local production function is of the Cobb-Douglas type, where Hicks-neutral technological progress is introduced. Parameter $\mu_{j}$ based on 1970-1975 data is extended to the period 1975-1985.

2) Predicted changes $\rho^{i}$ of the unit load of environmental factor $i\left(\mathrm{COD}, \mathrm{SO}_{2}\right)$ are based on trends in actual data in the Pollution White Paper for Osaka Prefecture (1977). For water, an increase of 20 percent for 10 years is assumed (Table I).

3) Capital coefficients and rates of distribution are constant over the time period.

4) Environmental restrictions change over time (Table II).

5) For frictional constraints $\pi=0.102, \pi^{\prime}=0.067$ in Osaka and $\pi=0.071, \pi^{\prime}=0.139$ in other regions. (For ten years, $(-) 40$ percent, 40 percent, and $(-) 30$ percent, 100 percent each).

6) Calculated values of parameters $A_{j}, b_{j}, \mu_{j}$ and $k_{j}$ in Osaka City are shown in Table III. (See Appendix.)

Third, the Lagrangian multipliers are obtained as dual optimal solutions. Optimally the Lagrangian multiplier $\lambda_{i}^{j}$ corresponding to the target constraint $i$ in the subproblem $j$, can be interpreted as an incremental price of the constraint
TABLE I

Predicted Change in the Unit Load of Environmental and ReSOURCE Factors (For Every Two Years)

\begin{tabular}{|c|c|c|}
\hline \multicolumn{3}{|l|}{$\underline{C O D}$} \\
\hline Osaka city & $(-)$ & 7.58 \\
\hline others & $(-)$ & 3.28 \\
\hline \multicolumn{3}{|l|}{$\mathrm{SO}_{2}$} \\
\hline Osaka city & $(-)$ & $10.0 \%$ \\
\hline others & $(-)$ & 6.68 \\
\hline \multicolumn{3}{|l|}{ Water } \\
\hline Osaka & & $3.7 \%$ \\
\hline others & & $3.7 \%$ \\
\hline \multicolumn{3}{|l|}{ Land } \\
\hline Osaka & & istant \\
\hline others & & astant \\
\hline
\end{tabular}


TABLE II

EnVironmental Restrictions in 1985 (Reduction Rate from 1973

VALUE).

\begin{tabular}{lccccc}
\hline & \multicolumn{1}{c}{$\mathrm{COD}$} & $\mathrm{SO}_{2}$ & Land & Water \\
\hline Osaka & $(-) 388$ & $(-) 478$ & $(+) 288$ & $(-) \quad 98$ \\
Yao & $(-) 268$ & $(-) 478$ & $(-) 138$ & $(-) 408$ \\
Daito & $(-) 318$ & $(-) 318$ & $(-) 58$ & $(-) 408$ \\
Higashi Osaka & $(-) 268$ & $(-) 378$ & $(-) 108$ & $(-) 328$ \\
\hline
\end{tabular}

TABLE III

Calculated Values of Parameters $A_{j}, b_{j}, \mu_{j}$ and $k_{j}$ In Osaka City

\begin{tabular}{|c|c|c|c|c|}
\hline Industry (j) & $A_{j}$ & $\mathrm{~b}_{j}$ & ${ }^{\mu}{ }_{j}$ & $k_{j}$ \\
\hline 1 & 10.20 & 0.1145 & 0.067 & 0.1195 \\
\hline 2 & 8.59 & 0.1391 & 0.004 & 0.1160 \\
\hline 3 & 14.46 & 0.1566 & 0.062 & 0.0716 \\
\hline 4 & 6.10 & 0.1779 & 0. & 0.1599 \\
\hline 5 & 9.99 & 0.1723 & 0. & 0.0926 \\
\hline 6 & 5.46 & 0.1540 & 0. & 0.1868 \\
\hline 7 & 6.81 & 0.2291 & 0.058 & 0.1824 \\
\hline 8 & 7.87 & 0.1294 & 0.006 & 0.1400 \\
\hline 9 & 6.60 & 0.1479 & 0.020 & 0.1735 \\
\hline 10 & 9.27 & 0.1737 & 0.027 & 0.1125 \\
\hline 11 & 14.03 & 0.1445 & 0.033 & 0.0670 \\
\hline 12 & 5.95 & 0.1865 & 0.031 & 0.1926 \\
\hline 13 & 6.49 & 0.1216 & 0. & 0.1746 \\
\hline 14 & 8.18 & 0.0870 & 0. & 0.1077 \\
\hline 15 & 6.84 & 0.1981 & 0.002 & 0.1486 \\
\hline 16 & 7.11 & 0.2000 & 0.044 & 0.1659 \\
\hline 17 & 9.67 & 0.1588 & 0.003 & 0.1020 \\
\hline 18 & 7.24 & 0.1841 & 0.012 & 0.1491 \\
\hline 19 & 7.00 & 0.2107 & 0. & 0.1394 \\
\hline 20 & 8.33 & 0.1677 & 0.017 & 0.1228 \\
\hline
\end{tabular}

constant measured in a unit of the objective at the lower level. Thus, the value of the $\lambda_{i}^{j}$ is considered as a measure or index of the degree of difficulty in achieving target constraints at the local level.

Fourth, the Lagrangian multipliers are positive-linearly transformed to the utility concept. Numerical results are shown in Table IV. For example, in Osaka, it is known that land and water constraints are the worst difficulties to be met in terms of the local objective or local production functions. In Yao, $\mathrm{COD}$ and $\mathrm{SO}_{2}$ are the worst. However, these difficulties are decreasing.

Fifth, the basic component utility functions are nested into the multiattribute utility functions. This process is executed at the second level, and relative weights for numerical values of analytical solutions are assigned by subjective judgments of the decisionmaker. Rational procedures for subjective judgment are pursued using algorithms of decision analysis such as fifty-fifty chance lottery techniques or canonical indifference lottery experiments. Under assump- tions of preferential as well as utility independence, the numerical representation of multiattribute utility functions $U^{j}$ is generally presented in multiplicative form [14], [15]:

$$
1+K^{j} U^{j}=\prod_{i=1}^{m}\left(1+K^{j} k_{i} u_{i}\right)
$$

or

$$
U^{j}=1 / a_{0}\left[\prod_{i=1}^{m}\left(1+a_{i} u_{i}\right)-1\right]
$$

where $a_{0}=K^{j}$ and $a_{i}=K^{j} k_{i} \cdot k_{i}, K^{j}$ are scaling constants, and $\sum_{i=1}^{m} k_{i} \neq 1,0<k_{i}<1$ and $K^{j}>-1$.

In calculating the scaling constants, the indifference experiments are carried out in terms of the component utility functions (CUF), which allows the experiments to be performed more efficiently than in terms of attributes because numerical ranges of the CUF are already normalized between 0 and 1 . Assessed parameters in formulation (24) are shown in Table V.

Sixth, the numerical values of these utility functions in present situations are calculated at each level (Table VI).

By examining these numerical values, which are already normalized in commensurate terms of utility values, the decisionmaker can find the order and magnitude of difficulties that will be encountered when attempting to fulfill the environmental or resource constraints. Note that these assessments are performed in terms of the local objective functions, so that the values can be utilized for decision support in making policies on local environmental management.

In addition, by the NLM method the decisionmaker can simultaneously obtain primal optimal solutions when he obtains dual optimal solutions in the first layer. For example, in the environmental management program, an optimal capital (or industrial) reallocation plan is combined with the systems evaluation, as is shown in Fig. 6. Thus simultaneous determination of the evaluation, derived from dual optimal solutions, and the optimal allocation of resources, derived from primal optimal solutions, are main advantages of the NLM method.

As a result of these solutions, the total capital value of manufacturing industries in Osaka would increase 3.5 percent by the end of the planning period. The average increase 
TABLE IV

Assessment of Utility for Environmental Management Program in the Regions

\begin{tabular}{|c|c|c|c|c|c|c|c|c|c|c|}
\hline & \multicolumn{2}{|c|}{$t=1$} & \multicolumn{2}{|c|}{$t=2$} & \multicolumn{2}{|c|}{$t=3$} & \multicolumn{2}{|c|}{$t=4$} & \multicolumn{2}{|c|}{$t=5$} \\
\hline & $\lambda$ & $\mathrm{u}$ & $\lambda$ & $\mathrm{u}$ & $\lambda$ & u & $\lambda$ & u & $\lambda$ & u \\
\hline \multicolumn{11}{|l|}{ Osaka } \\
\hline $\begin{array}{l}\mathrm{COD} \\
\mathrm{SO}_{2}\end{array}$ & $\begin{array}{l}43.34 \\
47.17\end{array}$ & $\begin{array}{l}0.85 \\
0.94\end{array}$ & $\begin{array}{r}15.82 \\
0.08\end{array}$ & $\begin{array}{l}0.16 \\
0.00\end{array}$ & $\begin{array}{r}83.15 \\
343.96\end{array}$ & $\begin{array}{l}0.21 \\
0.86\end{array}$ & $\begin{array}{l}50.81 \\
67.19\end{array}$ & $\begin{array}{l}0.70 \\
0.96\end{array}$ & $\begin{array}{l}56.30 \\
74.88\end{array}$ & $\begin{array}{l}0.68 \\
0.93\end{array}$ \\
\hline $\begin{array}{l}\text { Land } \\
\text { Water }\end{array}$ & $\begin{array}{r}7.21 \\
12.51\end{array}$ & $\begin{array}{l}0.05 \\
0.17\end{array}$ & $\begin{array}{l}96.69 \\
72.37\end{array}$ & $\begin{array}{l}0.97 \\
0.72\end{array}$ & $\begin{array}{r}6.96 \\
25.34\end{array}$ & $\begin{array}{l}0.02 \\
0.06\end{array}$ & $\begin{array}{r}23.76 \\
7.31\end{array}$ & $\begin{array}{l}0.29 \\
0.04\end{array}$ & $\begin{array}{r}24.76 \\
8.44\end{array}$ & $\begin{array}{l}0.24 \\
0.02\end{array}$ \\
\hline \multicolumn{11}{|l|}{$\underline{\text { Yao }}$} \\
\hline $\begin{array}{l}\mathrm{COD} \\
\mathrm{SO}_{2}\end{array}$ & $\begin{array}{l}1.42 \\
0.24\end{array}$ & $\begin{array}{l}0.09 \\
0.02\end{array}$ & $\begin{array}{l}1.05 \\
1.98\end{array}$ & $\begin{array}{l}0.07 \\
0.13\end{array}$ & $\begin{array}{l}1.57 \\
0.04\end{array}$ & $\begin{array}{l}0.09 \\
0.00\end{array}$ & $\begin{array}{l}0.00 \\
2.42\end{array}$ & $\overline{0.05}$ & $\begin{array}{r}5.56 \\
23.79\end{array}$ & $\begin{array}{l}0.08 \\
0.39\end{array}$ \\
\hline $\begin{array}{l}\text { Land } \\
\text { Water }\end{array}$ & $\begin{array}{r}10.85 \\
3.27\end{array}$ & $\begin{array}{l}0.72 \\
0.22\end{array}$ & $\begin{array}{r}8.09 \\
12.65\end{array}$ & $\begin{array}{l}0.54 \\
0.84\end{array}$ & $\begin{array}{r}8.31 \\
14.80\end{array}$ & $\begin{array}{l}0.46 \\
0.82\end{array}$ & $\begin{array}{r}8.60 \\
26.05\end{array}$ & $\begin{array}{l}0.26 \\
0.86\end{array}$ & $\begin{array}{r}5.53 \\
57.54\end{array}$ & $\begin{array}{l}0.08 \\
0.96\end{array}$ \\
\hline \multicolumn{11}{|l|}{ Daito } \\
\hline $\begin{array}{l}\mathrm{COD} \\
\mathrm{SO}_{2}\end{array}$ & $\begin{array}{l}1.43 \\
2.00\end{array}$ & $\begin{array}{l}0.06 \\
0.10\end{array}$ & $\begin{array}{l}106.64 \\
370.18\end{array}$ & $\begin{array}{l}0.12 \\
0.71\end{array}$ & $\begin{array}{l}265.58 \\
409.20\end{array}$ & $\begin{array}{l}0.52 \\
0.81\end{array}$ & $\begin{array}{l}282.34 \\
453.02\end{array}$ & $\begin{array}{l}0.56 \\
0.90\end{array}$ & $\begin{array}{l}285.91 \\
460.23\end{array}$ & $\begin{array}{l}0.56 \\
0.92\end{array}$ \\
\hline $\begin{array}{l}\text { Land } \\
\text { Water }\end{array}$ & $\begin{array}{r}0.00 \\
13.42\end{array}$ & $\overline{0.89}$ & $\begin{array}{r}72.40 \\
111.71\end{array}$ & $\begin{array}{l}0.05 \\
0.14\end{array}$ & $\begin{array}{r}24.98 \\
133.73\end{array}$ & $\begin{array}{l}0.03 \\
0.25\end{array}$ & $\begin{array}{r}25.43 \\
138.26\end{array}$ & $\begin{array}{l}0.03 \\
0.26\end{array}$ & $\begin{array}{r}25.99 \\
133.44\end{array}$ & $\begin{array}{l}0.03 \\
0.25\end{array}$ \\
\hline \multicolumn{11}{|c|}{ Higash1-0saka } \\
\hline $\begin{array}{l}\mathrm{COD} \\
\mathrm{SO}_{2}\end{array}$ & $\begin{array}{r}82.76 \\
0.00\end{array}$ & 0.31 & $\begin{array}{l}7.98 \\
0.60\end{array}$ & $\begin{array}{l}0.79 \\
0.03\end{array}$ & $\begin{array}{r}0.00 \\
60.06\end{array}$ & $\overline{-} .85$ & $\begin{array}{r}9.98 \\
50.69\end{array}$ & $\begin{array}{l}0.09 \\
0.83\end{array}$ & $\begin{array}{l}28.95 \\
11.52\end{array}$ & $\begin{array}{l}0.80 \\
0.22\end{array}$ \\
\hline $\begin{array}{l}\text { Land } \\
\text { Water }\end{array}$ & $\begin{array}{r}43.61 \\
174.05\end{array}$ & $\begin{array}{l}0.08 \\
0.85\end{array}$ & $\begin{array}{l}8.32 \\
0.00\end{array}$ & $\begin{array}{c}0.83 \\
-\end{array}$ & $\begin{array}{r}8.56 \\
13.08\end{array}$ & $\begin{array}{l}0.05 \\
0.12\end{array}$ & $\begin{array}{r}7.81 \\
10.69\end{array}$ & $\begin{array}{l}0.05 \\
0.10\end{array}$ & $\begin{array}{r}6.43 \\
22.14\end{array}$ & $\begin{array}{l}0.05 \\
0.57\end{array}$ \\
\hline
\end{tabular}

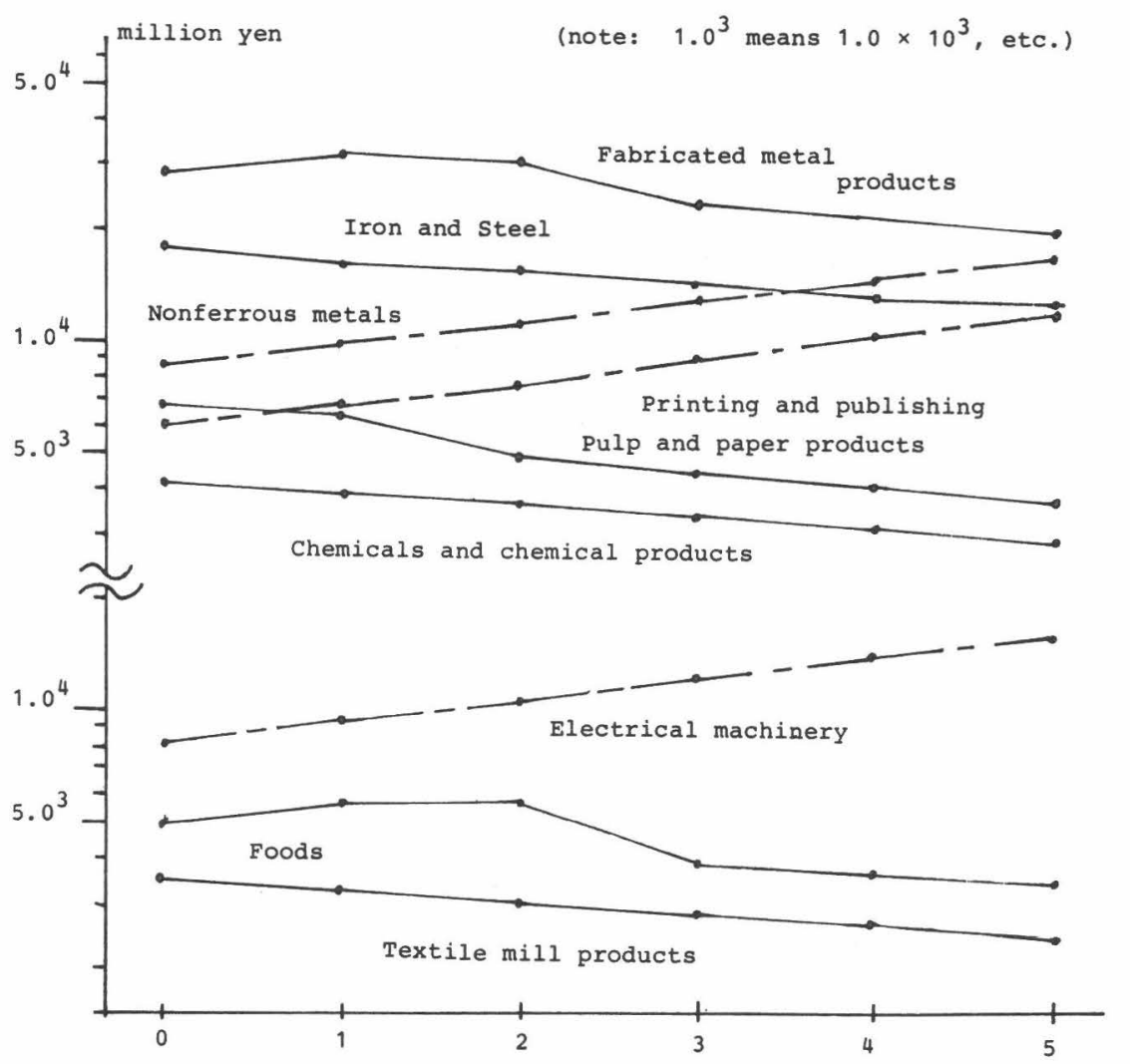

Fig. 6. Predicted trend of capital formation in Higashi-Osaka. 
TABLE $V$

Parameters of Multiattribute Utility Functions

\begin{tabular}{|c|c|c|c|c|c|c|c|c|c|c|c|c|c|c|c|}
\hline \multirow[b]{3}{*}{ Osaka: } & \multicolumn{5}{|c|}{ short term: $t=1,2$} & \multicolumn{5}{|c|}{ intermediate term: $t=3,4$} & \multicolumn{4}{|c|}{ long term: $t=5$} & \multirow[b]{2}{*}{$u_{2}$} \\
\hline & $a_{0}$ & ${ }^{a}{ }_{1}$ & $\mathrm{u}_{1}$ & $a_{2}$ & $u_{2}$ & ${ }^{a}{ }_{0}$ & $a_{1}$ & $u_{1}$ & $a_{2}$ & $u_{2}$ & $a_{0}$ & $\mathrm{a}_{1}$ & u & $a_{2}$ & \\
\hline & & & & & & & & & & & & & & & \\
\hline $\mathrm{U}_{\mathrm{OS}}$ & -0.2083 & -0.1666 & $u_{\text {env }}$ & -0.0500 & $u_{\text {res }}$ & 0.3207 & 0.2245 & uenv & 0.0786 & $u_{\text {res }}$ & 1.1111 & 0.6667 & $\mathrm{u}_{\text {env }}$ & 0.2667 & $u_{\text {res }}$ \\
\hline $\mathrm{U}_{\text {env }}$ & -0.2083 & -0.0500 & ${ }^{\mathrm{u}} \mathrm{COD}$ & -0.1666 & $\mathrm{u}_{\mathrm{SO}_{2}}$ & -0.2222 & -0.0667 & ${ }^{\mathrm{u}} \mathrm{COD}$ & -0.1667 & $\mathrm{u}_{\mathrm{SO}}$ & -0.4082 & -0.1714 & ${ }^{u} \mathrm{CoD}$ & -0.2857 & $\mathrm{u}_{\mathrm{SO}_{2}}$ \\
\hline$u_{\text {res }}$ & -0.6633 & -0.3714 & $u_{1 \text { and }}$ & -0.4643 & $u_{\text {water }}{ }^{2}$ & -0.6983 & -0.3666 & $u_{\text {land }}$ & -0.5237 & u ${ }^{2}{ }^{2}$ & -0.7292 & -0.3500 & $u_{1 \text { an }}$ & -0.5834 & $u_{\text {water }}^{2}$ \\
\hline \multicolumn{16}{|l|}{ Yao: } \\
\hline $\mathrm{U}_{\mathrm{YA}}$ & 0.3125 & 0.2500 & u env & 0.0500 & $u_{\text {res }}$ & 0.4445 & 0.3334 & $u_{\text {env }}$ & 0.0833 & $u_{\text {res }}$ & 0.6122 & , 0.4285 & $u_{\text {env }}$ & 0.1236 & u $_{\text {res }}$ \\
\hline $\mathrm{U}_{\text {env }}$ & -0.4082 & -0.1714 & ${ }^{\mathrm{u}} \mathrm{COD}$ & -0.2857 & $\mathrm{u}_{\mathrm{SO}}$ & -0.6984 & -0.3667 & ${ }^{\mathrm{u}} \mathrm{COD}$ & -0.5238 & $\mathrm{u}_{\mathrm{SO}}$ & -0.8035 & -0.4500 & ${ }^{\mathrm{u}} \mathrm{COD}$ & -0.6428 & $\mathrm{u}_{\mathrm{SO}}$ \\
\hline $\mathrm{U}_{\text {res }}$ & -0.0079 & -0.0033 & $u_{l a n d}$ & -0.0047 & uater & -0.4866 & -0.2214 & $u_{\text {land }}$ & -0.3406 & u 2 water & -0.7292 & -0.3500 & ulan & -0.5834 & $\begin{array}{l}u_{\text {water }} \\
2\end{array}$ \\
\hline \multicolumn{16}{|l|}{ Daito: } \\
\hline$\overline{\mathrm{U}_{\mathrm{DA}}}(\star)$ & 0.0 & 0.8 & $u_{\text {env }}$ & 0.2 & ures $_{\text {res }}$ & 0.1481 & 0.1111 & $u_{\text {env }}$ & 0.0333 & $u_{\text {res }}$ & 0.3207 & 0.2245 & $u_{\text {env }}$ & 0.0786 & $u_{\text {res }}$ \\
\hline$U_{\text {env }}$ & -0.2041 & -0.0714 & ${ }^{\mathrm{u}} \mathrm{COD}$ & -0.1429 & - $\mathrm{u}_{\mathrm{SO}}$ & -0.5926 & -0.2667 & ${ }^{\mathrm{u}} \mathrm{COD}$ & -0.4445 & $\mathrm{u}_{\mathrm{SO}}$ & -0.8036 & -0.4500 & ${ }^{\mathrm{u}} \mathrm{coD}$ & -0.6429 & $\mathrm{u}_{\mathrm{SO}_{2}}$ \\
\hline$U_{\text {res }}$ & -0.079 & -0.0332 & ${ }^{u}$ land & -0.0474 & $u_{\text {water }}$ & -0.4866 & -0.2214 & $u_{1 a n d}$ & -0.3406 & $u_{\text {water }}{ }^{2}$ & -0.7292 & -0.3500 & $u_{1 a n}$ & -0.5834 & $u_{\text {water }}$ \\
\hline \multicolumn{16}{|c|}{ Higashi-Osaka: } \\
\hline $\mathrm{U}_{\mathrm{HG}}$ & -0.2083 & -0.1666 & $u_{\text {env }}$ & -0.0500 & $u_{\text {res }}$ & -0.0635 & -0.0476 & uenv & -0.0167 & $\mathrm{u}_{\text {res }}$ & 0.3453 & 0.2314 & $u_{\text {env }}$ & 0.0925 & $u_{\text {res }}$ \\
\hline $\mathrm{U}_{\text {env }}$ & -0.2083 & -0.0500 & ${ }_{\mathrm{COD}}$ & -0.1666 & $\mathrm{u}_{\mathrm{SO}_{2}}$ & -0.2222 & -0.0667 & ${ }^{\mathrm{u}} \mathrm{COD}$ & -0.1667 & $\mathrm{u}_{\mathrm{sO}}$ & -0.2041 & -0.0714 & ${ }_{\mathrm{u}}^{\mathrm{COD}}$ & -0.1429 & $\mathrm{u}_{\mathrm{S}}$ \\
\hline $\mathrm{U}_{\text {res }}$ & -0.3550 & -0.1615 & $u_{1 \text { and }}$ & -0.2308 & $u_{\text {water }}$ & -0.4082 & -0.1714 & $\mathrm{u}_{\text {land }}$ & -0.2857 & $u_{\text {water }} 2$ & -0.4675 & -0.1800 & $u_{1 a n}$ & -0.3506 & $u_{\text {water }}{ }^{2}$ \\
\hline$\frac{\text { East Osaka }}{\mathrm{U}_{\mathrm{E} 0}}$ & \multicolumn{5}{|c|}{$\begin{array}{c}1 /-0.1587\left[\left(1-0.0952 \mathrm{v}_{\mathrm{YAO}}\right)\left(1-0.0381 \mathrm{U}_{\mathrm{DA}}\right)\right. \\
\left.\left(1-0.0333 \mathrm{U}_{\mathrm{HG}}\right)-1\right]\end{array}$} & \multicolumn{5}{|c|}{$\begin{array}{c}1 /-0.3067\left[\left(1-0.1840 \mathrm{U}_{\mathrm{YAO}}\right)\left(1-0.0828 \mathrm{U}_{\mathrm{DA}}\right)\right. \\
\left.\left(1-0.0736 \mathrm{U}_{\mathrm{HG}}\right)-1\right]\end{array}$} & \multicolumn{5}{|c|}{$\begin{array}{c}1 /-0.4228\left[\left(1-0.2537 U_{\mathrm{YAO}_{\mathrm{AO}}}\right)\left(1-0.1268 \mathrm{U}_{\mathrm{DA}}\right)\right. \\
\left.\left(1-0.1142 \mathrm{U}_{\mathrm{HG}}\right)-1\right]\end{array}$} \\
\hline$\frac{\text { Region: }}{U_{R}}$ & 0.6122 & 0.4285 & ${ }^{u}$ os & 0.1286 & "EO & 0.8283 & 0.5384 & ${ }^{\mathrm{u}} \mathrm{OS}$ & 0.1884 & $\mathrm{u}_{\mathrm{EO}}$ & 1.1111 & 0.6667 & ${ }^{\mathrm{u}} \mathrm{OS}$ & 0.2667 & $\mathrm{u}_{\mathrm{EO}}$ \\
\hline
\end{tabular}

* Additive form: $u=a_{1} u_{1}+a_{2} u_{2}$

TABLE VI

Numerical Evaluation of Environmental Management Program: 1975

\begin{tabular}{|c|c|c|c|}
\hline & $\begin{array}{l}\text { short term } \\
(t=1)\end{array}$ & $\begin{array}{l}\text { intermediate } \\
\text { term }(t=3)\end{array}$ & $\begin{array}{l}\text { long term } \\
(t=5)\end{array}$ \\
\hline Osaka & 0.0285 & 0.0110 & 0.0038 \\
\hline environment & 0.7518 & 0.6452 & 0.6509 \\
\hline COD & 0.85 & 0.21 & 0.68 \\
\hline $\mathrm{SO}_{2}$ & 0.94 & 0.86 & 0.93 \\
\hline resources & 0.1190 & 0.0450 & 0.0160 \\
\hline land & 0.05 & 0.02 & 0.24 \\
\hline water & 0.17 & 0.16 & 0.02 \\
\hline$\underline{\mathrm{Yao}}$ & 0.0209 & 0.1076 & 0.1613 \\
\hline environment & 0.0140 & 0.0473 & 0.3120 \\
\hline COD & 0.09 & 0.09 & 0.08 \\
\hline $\mathrm{SO}_{2}$ & 0.02 & 0.00 & 0.39 \\
\hline resources & 0.1309 & 0.5740 & 0.7680 \\
\hline 1and & 0.72 & 0.46 & 0.08 \\
\hline water & 0.22 & 0.82 & 0.96 \\
\hline Daito & 0.1628 & 0.0393 & 0.0490 \\
\hline environment & 0.0700 & 0.6076 & 0.7360 \\
\hline COD & 0.06 & 0.52 & 0.56 \\
\hline $\mathrm{SO}_{2}$ & 0.10 & 0.81 & 0.92 \\
\hline resources & 0.5340 & 0.1750 & 0.2000 \\
\hline land & - & 0.03 & 0.03 \\
\hline water & 0.89 & 0.25 & 0.25 \\
\hline Higashi-Osaka & 0.1326 & 0.0221 & 0.1145 \\
\hline environment & 0.0744 & 0.6377 & 0.1540 \\
\hline COD & 0.31 & - & 0.80 \\
\hline $\mathrm{SO}_{2}$ & - & 0.85 & 0.22 \\
\hline resources & 0.5526 & 0.0840 & 0.4275 \\
\hline land & 0.08 & 0.05 & 0.05 \\
\hline water & 0.85 & 0.12 & 0.57 \\
\hline \multicolumn{4}{|c|}{ East Osaka (Yao, Daito, Higashi-Osaka) } \\
\hline \multicolumn{3}{|c|}{ Region (Osaka, East Osaka) } & 0.0074 \\
\hline
\end{tabular}

in the total shipment of manufactured products for each two-year subperiod would be 14 percent. In the other cities, total capital values would increase 11.0 percent, 17.7 percent and 8.9 percent in Yao, Daito, and Higashi-Osaka, respectively. The total shipments would increase 25.6 percent, 23.8 percent and 10.1 percent every two years in these cities. These are consequences of introducing technical progress for increasing the production efficiency into local production functions and for decreasing the unit load of pollutants discharge into the constraints. Thus in this dynamic model it is seen that economic growth and environmental management can to some extent be compatible.

\section{Concluding Remarks}

The nested Lagrangian multiplier method is one approach which intends to consolidate the analytical and the subjective phase of decisionmaking processes.

In this paper a device for consolidating subjective judgments for systems coordination with analytical solutions obtained by mathematical optimization has been presented.

An eminent characteristic of mathematical programming is to provide an optimal design for allocation problems simultaneously along with a systems evaluation. In our problem the primal optimal solutions constitute an industrial reallocation plan under environmental management policies for each subregion.

The method also includes devices for evaluating noncommensurable attributes in a commensurate term and for compromising each evaluation which is often in conflict with another. Because the numerical values of the shadow 
TABLE VII

Classification OF INDUSTRIES

\begin{tabular}{clcl}
\hline Code & Industries & Code & Industries \\
\hline 1 & Foods & 11 & Leather products \\
2 & Textiles & 12 & Clay and stone products \\
3 & Apparel products & 13 & Iron and sttl \\
4 & Lumber and products & 14 & Nonferrous metals \\
5 & Furniture & 15 & Fabricated metal products \\
6 & Pulp and paper products & 16 & Machinery \\
7 & Printing and publishing & 17 & Electrical machinery \\
8 & Chemicals and products & 18 & Transportation equipment \\
9 & Coal and petroleum products & 19 & Precision machinery \\
10 & Rubber products & 20 & Miscellaneous \\
\hline
\end{tabular}

prices correspond to preference ordering of the decisionmaker, the values are used as inverse images of component utility functions. All the noncommensurate criteria functions were commensurated in terms of the utility concept. The trade-offs among conflicting criteria are explicitly depicted and compromised with means of decision analysis. Using the dual optimal solutions which have been normalized in terms of utility, the decisionmaker can examine and compare the degree of satisfaction for environmental management policies at the local level. He can detect some fields which have some difficulties in each subregion, and plan policies for overcoming them in the stratified levels.

In the NLM method the preferred solutions based on analytical solutions form mathematical programming could be obtained without any comprehensive derivation of a noninferior region.

Moreover, the formulation of mathematical programming in the lower layer has an additional merit. Because an additive or multiplicative representation of the MUF depends on independence assumptions, mathematical partition of an overall system into separate subsystems contributes to assuring the independence of the preferences. Because of this, utilization of shadow prices as inverse image of utility functions will prove to be a valuable device for utility analysis.

The effectiveness of this method depends on computational efficiency in solving problems of mathematical programming. In the case of complex problems such as regional planning, large-scale mathematical programming is usually troublesome to execute. Especially, because convexity cannot usually be insured, convergence of nonlinear programming is often difficult. Although a combination of this method with decomposition algorithms is recommended, many problems in this area remain unsolved as yet. Moreover a dynamic extension of this method using the maximum principle can be expected. The co-state variables in Hamiltonian function can be interpreted as the shadowprices in an analogous way to the Lagrangian multipliers in the NLM method. Efficient algorithms for this device will be expected.

\section{APPENDIX}

Data have been obtained mainly from the Industrial Statistics Survey Result Table in 1975 (the Statistical Office of Osaka Prefecture); Census of Manufactures: 1975 Report of Industrial Land and Water (the Research and Statistics Department, Minister's Secretariat, Ministry of International Trade and Industry), White Paper on Pollution in Osaka Prefecture in 1977 (Life and Environmental Division, Osaka Prefecture), and the Input-Output Table for Industrial Pollution Analysis in the Area in 1973 (Osaka Bureau of Trade and Industry), all in Japanese.

The classification of industries is shown in Table VII.

\section{REFERENCES}

[1] K. J. Arrow, Social Choice and Individual Values. New Haven: Yale Univ., 1951.

[2] —, "A difficulty in the concept of social welfare," J. Political Economy, $58,1950$.

[3] J. L. Cohn and D. H. Marks, "A review and evaluation of multiobjective programming techniques," Water Resources Research, vol. 11, pp. 208-220, Apr. 1975.

[4] C. H. Coombs, R. M. Dawes, and A. Tversky, Mathematical Psychology. Englewood Cliffs, NJ: Prentice-Hall, 1970.

[5] J. S. Dyer, "An empirical investigation of a man-machine interactive approach to the solution of the multiple criteria problem," in Multiple Criteria Decision Making, J. L. Cochrane and M. Zeleny, Ed. Columbia, SC: Univ. of South Carolina, 1973.

[6] J. S. Dyer, "Interactive goal programming," Management Science, vol. 19(1), pp. 62-70, Mar. 1972.

[7] P. C. Fishburn, Utility Theory for Decision Making. New York: Wiley, 1970.

[8] A. M. Geoffrion, J. S. Dyer, and A. Freinberg, "An interactive approach for multicriterion optimization, with an application to the operation of an academic department," Management Science, vol. 19(4), pp. 357-368, Dec. 1972.

[9] Y. Y. Haimes and W. A. Hall, "Multiobjectives in water resource systems analysis: The surrogate worth trade-off method," Water Resources Research, vol. 10, pp. 615-624, Aug. 1974.

[10] Y. Y. Haimes, W. A. Hall, and H. T. Freedman, Multiobjective Optimization in Water Resources Systems: The Surrogate Worth Trade-off Method. New York: Elsevier, 1975.

[11] Y. Ijiri, Management Goals and Accounting for Control. Amsterdam: North Holland, 1965.

[12] M. D. Intriligator, Mathematical Optimization and Economic Theory. Englewood Cliffs, NJ: Prentice-Hall, 1971.

[13] S. Karlin, Mathematical Methods and Theory in Games, Programming, 
and Economics. Reading, Mass.: Addison-Wesley, 1959.

[14] R. Keeney, "Multiobjective utility functions," Oper. Research, vol. 22, pp. 22-34, Jan.-Feb. 1974.

[15] R. L. Keeney and H. Raiffa, Decisions with Multiple Objectives: Preferences and Value Trade-offs. New York: Wiley, 1976.

[16] L. S. Lasdon, "Duality and decomposition in mathematical programming," IEEE Trans. Systems Science and Cybernetics, vol. 4(2), pp. 86-100, Feb. 1968.

[17] - Optimization Theory for Large Systems. New York: Macmillan, 1970.

[18] L. S. Lasdon, R. L. Fox, and M. W. Ranter, "Nonlinear optimization using the generalized reduced gradient method," Revue Francaise d'Automatique, Informatique et Recherch Operationnelle, vol. 3, pp. 73-103, Nov. 1974

[19] L. S. Lasdon, A. D. Waren, A. Jain, and M. W. Ratner, "Design and testing of a generalized reduced gradient code for non-linear optimization," Tech. Memorandum No. 353, Case Western Reserve Univ., Mar. 1975.

[20] R. D. Luce and P.Suppes, "Preference, utility and subjective probability," in Handbook of Mathematical Psychology, R. D. Luce, R. R. Bush, and E. Galanter Eds. New York: Wiley, 1965, vol. III.

[21] D. G. Luenberger, Introduction to Linear and Nonlinear Programming. London: Addison-Wesley, 1973.
[22] M. D. Mesarovic, D. Macko, and Y. Takahara, Theory of Hierarchical, Multilevel Systems. New York: Academic, 1970.

[23] J. Von Neumann and O. Morgenstern, Theory of Games and Economic Behavior. New York: Wiley, 1944, 2nd ed. 1947.

[24] J. W. Pratt, H. Raiffa, and R. Schlaifer, "The foundation of decision under uncertainty: An elementary exposition," J. Am. Statistical Association, vol. 59, pp. 353-375, 1964.

[25] H. Raiffa, Decision Analysis. Reading, MA: Addison-Wesley, 1968.

[26] A. P. Sage, Methodology for Large Scale Systems. New York: McGraw-Hill, 1977.

[27] R. Schlaifer, Analysis of Decisions Under Uncertainty. New York: McGraw-Hill, 1969.

[28] F. Seo, "Evaluation and control of regional environmental systems in the Yodo River basin: Socio-economic aspects," in Proc. IF AC Symposium on Environmental Systems Planning, Design and Control. Oxford: Pergamon, 1977.

[29] F. Seo and M. Sakawa, "An evaluation method for environmental systems planning: An alternative utility approach," Environment and Planning, A,II(2), pp. 149-168, Feb. 1979.

[30] F. Seo, "An integrated approach for improving decision-making processes," WP-79-54, The International Institute for Applied Systems Analysis, Laxenburg, Austria, June 1979, to appear in Behavioral Science, 1980 (forthcoming). 